\title{
Target strength and retrieval-induced forgetting in semantic recall
}

\author{
JAMIE I. D. CAMPBELL \\ University of Saskatchewan, Saskatoon, Saskatchewan, Canada \\ AND \\ Thomas L. Phenix \\ Campion College at the University of Regina, Regina, Saskatchewan, Canada
}

\begin{abstract}
Retrieval-induced forgetting (RIF) occurs when practice of a memory item impairs retrieval of related, unpracticed items. Here, we demonstrated that RIF in semantic memory is retrieval dependent. University students either studied $(7 \times 8=56)$ or retrieved $(7 \times 8=$ ?) the answers to a set of multiplication problems for 40 blocks and then were tested on their addition counterparts $(7+8=$ ?). For the retrieval practice group, but not the study practice group, response time for the multiplication-practiced addition facts was about $100 \mathrm{msec}$ slower, relative to control addition problems, in the first of five postpractice addition blocks. Subsequent blocks of addition were interleaved with retrieval blocks of all the multiplication counterparts, which permitted measurement of RIF for the control addition problems after only a single retrieval of their multiplication counterparts. The control problems presented RIF in excess of $200 \mathrm{msec}$, much larger than the RIF observed after massive practice. This is consistent with the hypothesis that inhibition of competitors should be weaker when target strength is high than when target strength is only moderate (Anderson, 2003; Norman, Newman, \& Detre, 2007). The evidence that RIF in semantic retrieval is both retrieval dependent and weaker following massive target practice than following moderate target practice provides strong support for inhibition-based theories of RIF.
\end{abstract}

Retrieval-induced forgetting (RIF) is a pervasive and extensively studied phenomenon that reveals competitive dynamics of retrieval from long-term memory: Repeated cued retrieval of memory items impairs retrieval of related items that were not practiced (e.g., Anderson, Bjork, \& Bjork, 1994). RIF is observed in a wide variety of memory tasks (Johnson \& Anderson, 2004; Koutstaal, Schacter, Johnson, \& Galluccio, 1999; Levy \& Anderson, 2002; Phenix \& Campbell, 2004; Shaw, Bjork, \& Handal, 1995), but most involve variants of the retrieval practice paradigm (Anderson, 2005). In a typical experiment, participants study category-exemplar pairs (fruit-orange, fruit-apple, drink-rum, drink-scotch) and then receive retrieval practice trials on a subset of the studied items. Retrieval practice entails repeated cued-stem recall tests (e.g., fruit-or___ _ . This is followed by a cued recall test for all exemplars. Practice facilitates recall of the practiced items but impairs recall of unpracticed exemplars in the practiced categories, relative to unpracticed categoryexemplar pairs. RIF in the retrieval practice paradigm is most often studied using episodic recall (Anderson, 2003; Anderson \& Spellman, 1995; Norman, Newman, \& Detre, 2007) or recognition (Spitzer \& Bäuml, 2007), but it is also observed in semantic memory retrieval (Campbell \& Timm, 2000; Johnson \& Anderson, 2004). For example, Campbell and Timm demonstrated that retrieval of simple addition facts $(2+5=$ ?) is impaired by retrieval practice of related arithmetic facts (practicing $2 \times 5=10$; see also Phenix \& Campbell, 2004).

Two main alternative explanations have been proposed for RIF: inhibition (Anderson, 2003; Anderson, Bjork, \& Bjork, 2000; Norman et al., 2007; Phenix \& Campbell, 2004; Shivde \& Anderson, 2001) and associative interference (Camp, Pecher, \& Schmidt, 2007; Censabella \& Noël, 2004; see also C. M. MacLeod, Dodd, Sheard, Wilson, \& Bibi, 2003). According to inhibition accounts, retrieval practice generates inhibition of related memory items in order to reduce retrieval competition. For example, practicing the target $2 \times 5=$ ? would inhibit retrieval of the semantic competitor $2+5=7$, reducing performance on $2+5=$ ? In contrast, interference theory assumes that RIF occurs because practicing $2 \times 5=$ ? strengthens $2 \times 5$ $=10$, which blocks or dilutes activation of $2+5=7$. Retrieval of $2+5=7$ is, consequently, more difficult, even though it is not inhibited.

Attempts to experimentally discriminate interference and inhibitory accounts of RIF have focused on two theoretically critical issues: cue independence and retrieval dependence. Interference-based theories assume that RIF reflects a relative weakening of the cue-target associations of unpracticed competitors (e.g., Camp et al., 2007). This account explains RIF in terms of changes in the ef- 
fectiveness of the cue to retrieve unpracticed items. Several studies have yielded evidence, however, that RIF is observed when a related but unpracticed cue is used in the final recall test (e.g., Anderson \& Bell, 2001; Johnson \& Anderson, 2004). Evidence for cue independence challenges interference accounts and supports an inhibitionbased theory of RIF. Nonetheless, other researchers have provided evidence that RIF can be eliminated with independent cues (Camp et al., 2007; Perfect et al., 2004). Consequently, the results concerning cue independence do not uniformly support an inhibition account of RIF.

Anderson et al. (2000) introduced another approach to discriminate inhibition- and interference-based theories of RIF. Their rationale was based on the assumption that inhibition should depend on retrieval practice (i.e., actually retrieving the target, given a cue), because competition from related facts would occur only when retrieval is required. Thus, inhibition of competitors would be generated when retrieval is attempted, but not when a fact is only read or studied (cf. Blaxton \& Neely, 1983; Storm, Bjork, \& Bjork, 2006). Studying (but not retrieving) a fact, however, would be expected to increase its cue-target strength and produce interference. Consequently, if RIF is due to interference, it should be observed following either study or retrieval practice, whereas if RIF depends on inhibition, it should be retrieval dependent. Anderson et al. (2000; see also Bäuml, 2002; Bäuml \& Aslan, 2004; Ciranni \& Shimamura, 1999; Shivde \& Anderson, 2001) demonstrated, using an episodic memory task, that RIF occurred with retrieval practice, but not with study practice.

\section{The Present Experiment}

The present experiment had two purposes. First, we wanted to determine whether RIF in semantic memory (number fact retrieval) is retrieval dependent. Johnson and Anderson (2004) demonstrated RIF in semantic retrieval, but their experiment did not test retrieval dependency. This is important in order to establish the generality of retrievaldependent RIF. Therefore, in the present experiment; we manipulated the type of multiplication practice (e.g., retrieval $2 \times 5=$ ? vs. study $2 \times 5=10$ ) and then compared the effects of practice on the corresponding addition problems (e.g., $2+5=$ ?). Single-digit number pairs (e.g., $2,5)$ are associated with two primary facts in the context of addition $(2+5=7)$ and multiplication $(2 \times 5=10)$. To retrieve one of these facts when a retrieval cue $(2 \times 5$ $=$ ?) is given, interference from the other primary association $(2+5=7)$ must be overcome. If semantic retrieval inhibits interfering associations, retrieval practice of one of the primary arithmetic associations should reduce the accessibility of the other. Participants practiced a subset of multiplication problems for 40 blocks and then received the corresponding multiplication-practiced (MP) addition facts and multiplication-unpracticed (MU) addition facts. The MP addition problems are analogous to unpracticed items from the practiced categories in the standard RIF retrieval practice paradigm, whereas the MU addition problems are analogous to unpracticed baseline items from unpracticed categories. RIF would be expressed by relatively poor performance for MP addition facts, relative to the MU addition controls. If RIF reflects inhibition, addition performance should present RIF in the retrieval condition, but not in the study condition. If RIF in semantic retrieval is due only to interference, we would expect no differences in RIF between the retrieval and the study conditions.

Second, we pursued a novel prediction of the inhibitionbased neural network model of RIF proposed by Norman et al. (2007). An important and previously untested implication of the model is that when target strength is high, competitor inhibition should be relatively low (see Simulation 22, p. 915). This prediction for RIF appears to be closely linked to the principle of interference dependence: Competitor inhibition may occur only to the extent that interference needs to be resolved during retrieval of a target item (Anderson, 2003; Levy, McVeigh, Marful, \& Anderson, 2007). In this view, target retrieval is not sufficient to induce inhibition; in addition, the target must be susceptible to interference. Consistent with the predictions of the Norman et al. model, the principle of interference dependence implies that inhibition and RIF should decrease as target strength increases and susceptibility to interference is diminished. To implement inhibition, the model's learning algorithm punishes (i.e., weakens) competitor units that become active during retrieval. When targets are weak, competitors activate strongly and attract punishment, which results in strong RIF of competitors. When targets are very strong, however, competitors activate weakly and do not attract punishment. Consequently, in the model, inhibition and RIF are greater with weak targets than when target strength is very high (cf. Carr \& Dagenbach, 1990, 1994).

The study practice group in the present experiment provided a test of the prediction that, with retrieval practice held constant, RIF should be smaller in the context of very high target strength, relative to lower target strength. These participants studied (but did not retrieve) each MP multiplication target (e.g., $2 \times 5=10) 40$ times, which should have created high target strength. If RIF is retrieval dependent, we would expect no RIF for the study group in the first postpractice addition block, and performance on MU and MP addition problems should be equivalent. Following the first postpractice addition block, however, the study group performed retrieval of the MU multiplication counterparts for the first time. The study group should, therefore, present RIF in the second and subsequent postpractice addition blocks. Furthermore, if inhibition is low when target strength is high (Anderson 2003; Norman et al., 2007), RIF should be smaller for MP problems than for MU addition problems.

\section{METHOD}

\section{Participants}

Sixty-six University of Saskatchewan students (38 women) were recruited from the introductory psychology participant pool in return for bonus course credit. The participants were divided approximately evenly between the retrieval $(n=32)$ and the study $(n=34)$ groups. Age ranged from 17 to 43 years $(M=20.8$ years).

\section{Stimuli and Design}

There were eight MP addition problems (and their multiplication counterparts) composed of pairs of operands selected from 
among $2,5,7,8$ or $3,4,6,9$. The MU addition control problems were composed from the four operands not used for the MP set. Assignment of the $2 / 5 / 7 / 8$ and $3 / 4 / 6 / 9$ problem sets to the MP and MU conditions was counterbalanced across the retrieval and study groups. The $2 / 5 / 7 / 8$ set included $2+5=7,7+2=9,8+2=10$, $5+5=10,5+7=12,8+5=13,7+7=14$, and $7+8=15$ (or the corresponding multiplication problems), and the $3 / 4 / 6 / 9$ set included $3+4=7,6+3=9,4+4=8,4+6=10,9+3=12$, $9+4=13,6+6=12$, and $6+9=15$ (or their multiplication counterparts). Eight fillers were composed of one operand from the $2 / 5 / 7 / 8$ set and one from the $3 / 4 / 6 / 9$ set. The fillers were not counterbalanced; consequently, performance on the fillers could not be interpreted simply, relative to the practice and unpracticed conditions, and was not included for analysis.

There were three experimental phases (see Figure 1). In the prepractice test, the participants received 2 blocks of the 24 addition problems $(2+5=?)$. In the subsequent practice phase, the participants received 40 blocks of the 8 MP multiplication problems. In the practice phase, the participants in the retrieval group retrieved and stated aloud the answer to the multiplication problems (e.g., $2 \times 5=$ ?), whereas those in the study group read aloud the answer from presented equations (e.g., $2 \times 5=10$ ). The final postpractice test phase consisted of 9 blocks. Each posttest block involved all 24 number pairs, and the participants generated and stated aloud the correct addition or multiplication answer to each problem. The participants performed addition on odd-numbered posttest blocks and multiplication on even-numbered posttest blocks. The interleaving of addition and multiplication blocks allowed us to examine RIF for the MU addition problems after one to four retrieval practice trials with their multiplication counterparts.

In the pretest and posttest phases, the stimuli appeared in a 7-character horizontal field (e.g., $4+8=$ ). In the practice phase, the problems seen by the retrieval group occupied the same 7-character field $(4 \times 8=)$, whereas the study group's problems occupied a 10 -character field $(4 \times 8=24)$. All the stimuli appeared as white characters against a dark background, and the characters were approximately $3 \mathrm{~mm}$ wide and $5 \mathrm{~mm}$ high.

\section{Procedure}

The study took place in a quiet room, with an experimenter present, and required about $45 \mathrm{~min}$. The stimuli were displayed on a highresolution monitor connected to a PC-type computer. The participants wore a lapel microphone connected via the computer's parallel port, to control a software clock accurate to $\pm 1 \mathrm{msec}$. Instructions described the three phases. The first phase consisted of 2 blocks of 24 simple addition problems. For the subsequent practice phase, the participants in the study condition were told that they would receive 40 blocks of 8 multiplication equations, which included the correct multiplication answers. Their task on each trial was to study the equation and then say the presented answer aloud. The participants in the retrieval condition similarly were told that they would receive
40 blocks of 8 multiplication problems. Their task was to generate and state aloud the correct answer to each problem. Both groups were told that they would be tested on the practiced problems at a later point. The final posttest phase of the experiment had blocks of all 24 addition problems alternating with blocks of their multiplication counterparts until 5 addition blocks were completed. Problem order was random without replacement in each block. For both pretest and posttest trials, the participants were instructed to state the correct answer quickly, without sacrificing accuracy.

Each trial began with presentation of a 1-sec central fixation dot. The problem or equation then appeared, with the times or the addition sign at fixation. Timing began with the onset of the stimulus and continued until the participant's verbal response stopped the timer. When the response (or any sound) was detected, the stimulus was instantly removed from the screen. This allowed the experimenter to identify trials on which the microphone failed to detect response onset and to mark them as spoiled. The experimenter entered the participant's response, and the fixation dot immediately appeared to signal the start of the next trial. The participants received no feedback regarding speed or accuracy.

\section{RESULTS}

\section{Posttest Multiplication}

Interpretation of the retrieval versus study manipulation hinges on the study condition's producing at least as much strengthening of the practiced facts as does the retrieval condition. Otherwise, greater RIF for retrieval than for study practice might be attributable to strength-based interference, rather than to inhibition. We expected that 40 encounters with each multiplication problem during the practice phase, for either retrieval or study, would produce high target strength. Average response time (RT) for the retrieval group during the practice phase was $880 \mathrm{msec}$, whereas for the study group it was $733 \mathrm{msec}[F(1,64)=$ $\left.8.9, M S_{\mathrm{e}}=80,163, p=.004\right]$. Over the 40 practice blocks, this amounted to an additional $6 \mathrm{sec}$ of exposure to each multiplication fact for the retrieval group (35.2 $\mathrm{sec}$ in total, on average), relative to the study group $(29.3 \mathrm{sec})$. Although total exposure time per multiplication fact was greater with retrieval than with study, the posttest analysis indicated that this did not confer a performance advantage for the retrieval group. Block 1 of multiplication in the posttest provided the best opportunity in this experiment to compare the retrieval and the study groups' multiplication retrieval performance following the practice phase, although it followed a block of retrieval of the corresponding

\section{Pretest Blocks Practice Blocks}

\section{Posttest Blocks}

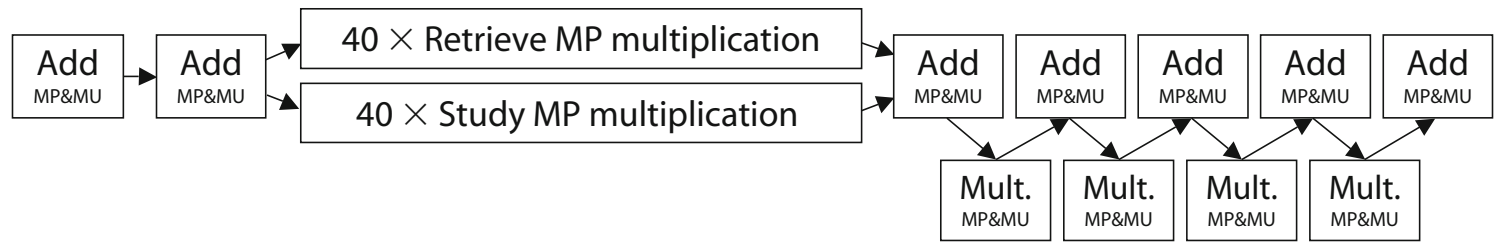

Figure 1. Design of the experiment. Both the multiplication-practiced (MP) and the multiplication-unpracticed (MU) operand pair addition problems $(2+5=$ ?) were tested in two randomized pretest blocks. The practice phase consisted of 40 blocks of multiplication retrieval $(2 \times 5=?)$ or multiplication study $(2 \times 5=10)$ of MP operand pairs. The posttest consisted of alternating blocks of addition and multiplication of both MP and MU pairs until 5 posttest addition blocks were completed. Posttest multiplication was retrieval $(2 \times 5=$ ? $)$ for all participants. 
Table 1

Group $\times$ Set Mean Response Times (RTs, in Milliseconds) and Error Rates $(\% \mathrm{E})$ for the First Multiplication Block of the Posttest

\begin{tabular}{cccccc}
\hline & \multicolumn{3}{c}{ Group } \\
\cline { 2 - 3 } \cline { 5 - 6 } & \multicolumn{2}{c}{ Retrieval } & & \multicolumn{2}{c}{ Study } \\
\cline { 2 - 3 } \cline { 5 - 6 } Problem Set & RT & & & RT & $\% \mathrm{E}$ \\
\hline Practiced & 928 & 3.9 & & 967 & 2.2 \\
Unpracticed & 1,191 & 5.9 & & 1,165 & 9.2 \\
\hline
\end{tabular}

addition problems. To assess strength following the practice phase, mean correct RTs and error rates for the first postpractice block of multiplication were submitted to a group (study or retrieval) by set (practiced or unpracticed) ANOVA. The corresponding means appear in Table 1.

The $3.6 \%$ of RTs that were more than two standard deviations from each participant's mean per condition were discarded as outliers. Another $4.7 \%$ of RTs were spoiled by failures of the microphone. As would be expected, after 40 blocks of practice, posttest performance on the practice set $(948 \mathrm{msec})$ was much faster than that on the unpracticed set $(1,178 \mathrm{msec})\left[F(1,64)=84.1, M S_{\mathrm{e}}=20,823\right.$, $p<.001]$. There was no evidence for a main effect of group $\left[F(1,64)<1, M S_{\mathrm{e}}=126,394, p=.92\right]$ or a set $\times$ group interaction $\left[F(1,64)=1.64, M S_{\mathrm{e}}=20,823, p=\right.$ $.20]$. Thus, 40 blocks of study or retrieval practice were equally effective in speeding up retrieval of the practiced multiplication facts.

The overall error rate was $5.3 \%$ for the first posttest multiplication block. The group $\times$ set ANOVA indicated that practiced problems produced fewer errors $(3.0 \%)$ than did unpracticed problems $(7.6 \%)\left[F(1,64)=10.3, M S_{\mathrm{e}}=\right.$ $64.2, p=.002]$, but multiplication error rates did not differ between the retrieval $(4.9 \%)$ and the study $(5.7 \%)$ groups $\left[F(1,64)=0.37, M S_{\mathrm{e}}=58.8, p=.54\right]$. The group $\times$ set interaction approached conventional significance $[F(1,64)=$ $\left.3.3, M S_{\mathrm{e}}=64.2, p=.08\right]$. As is shown in Table 1, this reflected a trend toward greater error savings for the study group (7.0\%) than for the retrieval group (2.0\%). This suggests that extra study, if anything, tended to strengthen multiplication items more than did retrieval practice.

\section{Addition Response Times}

For addition problems, $4.4 \%$ of correct RTs were discarded as outliers, and a further $3.6 \%$ were spoiled by failures of the microphone. Figure 2 presents mean correct addition RT as a function of problem set (MU addition, MP addition), group (retrieval or study), and block (last pretest block and five posttest blocks). A set $\times$ group $\times$ phase analysis that contrasted the last block of the pretest with the first block of the posttest (see Figure 2) confirmed a significant three-way interaction $[F(1,64)=$ $\left.4.32, M S_{\mathrm{e}}=4,250, p=.04\right]$. To decompose the interaction, separate set $X$ phase analyses were performed for the retrieval and study groups. As is illustrated in Figure 2 , there was a set $\times$ phase interaction for the retrieval group $\left[F(1,31)=9.31, M S_{\mathrm{e}}=5,227, p=.005\right]$, owing to longer mean RTs for the MP addition set than for the MU addition set in posttest Block 1. In contrast, for the study group, there was no evidence for the corresponding interaction $\left[F(1,33)=0.33, M S_{\mathrm{e}}=3,331, p=.57\right]$. A $t$ test confirmed longer Block 1 mean RTs for MP than for MU addition problems in the retrieval condition $[t(31)=$ 3.95, $S E=23.5, p<.001]$ but not in the study condition $[t(33)=0.61, S E=26.5, p=.55]$. Thus, the three-way interaction occurred because the retrieval group presented RIF in the first block of the posttest, whereas the study group did not.

The subsequent posttest addition blocks introduced a new RIF situation for MU addition problems. Both groups retrieved both MP and MU multiplication counterparts between each subsequent posttest addition block. If RIF is retrieval dependent, this multiplication retrieval practice should now create RIF for addition problems whose multiplication counterparts were not practiced during the practice phase (i.e., the MU addition set). Furthermore, if competitor inhibition is lower when target strength is high
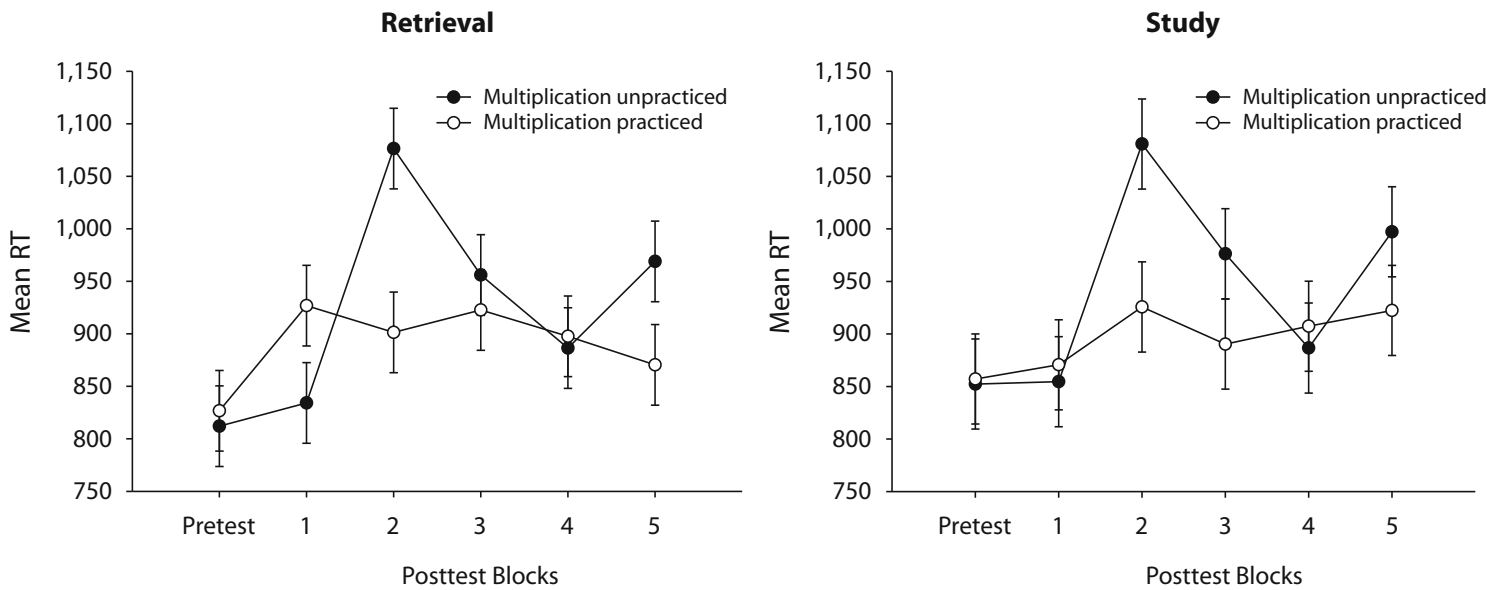

Figure 2. Mean correct addition response times (RTs, in milliseconds) as a function of group, set, and experimental block. Error bars are repeated measure $95 \%$ confidence intervals (Masson \& Loftus, 2003). 
(Anderson, 2003; Norman et al., 2007), we would expect RIF for MU addition to be greater than RIF for MP addition problems. This prediction is most clear for the study group because, although they studied MP multiplication counterparts extensively during the practice phase, the first retrieval of these problems presumably occurred between posttest addition Blocks 1 and 2. This allowed us to compare RIF when target strength was very high (MP condition) with RIF when target strength was moderate (MU condition), with target retrieval practice held constant.

A set $\times$ group $\times$ block ANOVA of the posttest data in Figure 2 indicated a robust set $\times$ block effect $[F(4,256)=$ $\left.17.43, M S_{\mathrm{e}}=14,145, p<.001\right]$. As Figure 2 shows, relative to MP addition problems, MU addition mean RT increased sharply $(235 \mathrm{msec})$ in posttest Block 2 relative to Block 1. This represents RIF resulting from retrieval of the MU addition problems' multiplication counterparts in the multiplication block interpolated between addition Blocks 1 and 2. Mean RTs then converged for the MU and MP problems over later blocks. A group $\times$ block analysis of posttest MU addition RTs indicated only a main effect of block $\left[F(4,256)=29.5, M S_{\mathrm{e}}=18,460, p<.001\right]$. There were no main or interaction effects involving the group factor $\left(F_{\mathrm{S}}<1\right)$.

In contrast, the corresponding group $\times$ block ANOVA of MP addition RTs indicated a group $\times$ block effect $\left[F(4,256)=2.72, M S_{\mathrm{e}}=11,498, p=.03\right]$. As Figure 2 shows, this interaction reflected, in large measure, an increase in MP addition RT between posttest Blocks 1 and 2 for the study group $(+55 \mathrm{msec})$, but not for the retrieval group $(-26 \mathrm{msec})\left[F(1,64)=3.88, M S_{\mathrm{e}}=13,770, p=\right.$ $.05]$. Thus, as is predicted by the hypothesis of retrievaldependent RIF, the study group exhibited evidence of RIF for MP addition problems in posttest addition Block 2 relative to Block 1, after their multiplication counterparts received retrieval practice for the first time between blocks. For the retrieval group, however, after 40 blocks of multiplication retrieval, one more multiplication retrieval trial did not affect RIF appreciably. Most important, as the right panel of Figure 2 shows, the study group presented much larger RIF for MU addition problems in posttest Block $2(+226 \mathrm{msec}$ increase relative to Block 1$)[t(33)=$ 5.57, $S E=40.6, p<.001]$ than for MP addition problems $(+55 \mathrm{msec})[t(33)=1.79, S E=30.7, p=.04$, onetailed]. Thus, with target retrieval practice held constant, RIF was smaller when target strength was high (MP condition) than when it was low (MU condition), as predicted by Norman et al. (2007).

\section{Addition Error Rates}

Figure 3 presents mean percentages of errors. The overall error rate for addition problems was $5.2 \%$. The error analyses were conducted to match the RT analyses. The set $\times$ group $\times$ phase (last block of pretest vs. posttest Block 1) ANOVA indicated only a main effect of phase $\left[F(1,64)=6.80, M S_{\mathrm{e}}=30.2, p=.01\right]$, with errors increasing from $4.4 \%$ in the last block of the pretest to $6.2 \%$ in the first posttest block. The three-way interaction was not significant $\left[F(1,64)=1.24, M S_{\mathrm{e}}=42.1, p=.27\right]$; therefore, there is no concern that the corresponding RT triple interaction in Figure 2 involved a speed-accuracy trade-off.

A set $\times$ group $\times$ block analysis of the posttest error data in Figure 3 indicated only a main effect of block $\left[F(4,256)=22.8, M S_{\mathrm{e}}=25.9, p<.001\right]$. Relative to the $6.2 \%$ overall error rate in posttest Block 1 , addition errors dropped to $1.7 \%$ during Blocks 2 and 3 and to $3.1 \%$ during Blocks 4 and 5. Since there was no evidence that error rates differed between MP and MU addition sets in posttest Block 2, the large RT disadvantage for MU relative to MP during posttest Block 2 (see Figure 2) cannot reflect different accuracy criteria.

To interpret RIF as inhibition, it is crucial that retrieval and study should create equal propensities to multiply; otherwise, addition performance differences could be attributed to retrieval interference. Above, we provided an analysis of the multiplication data to demonstrate that retrieval and study practice facilitated subsequent mul-
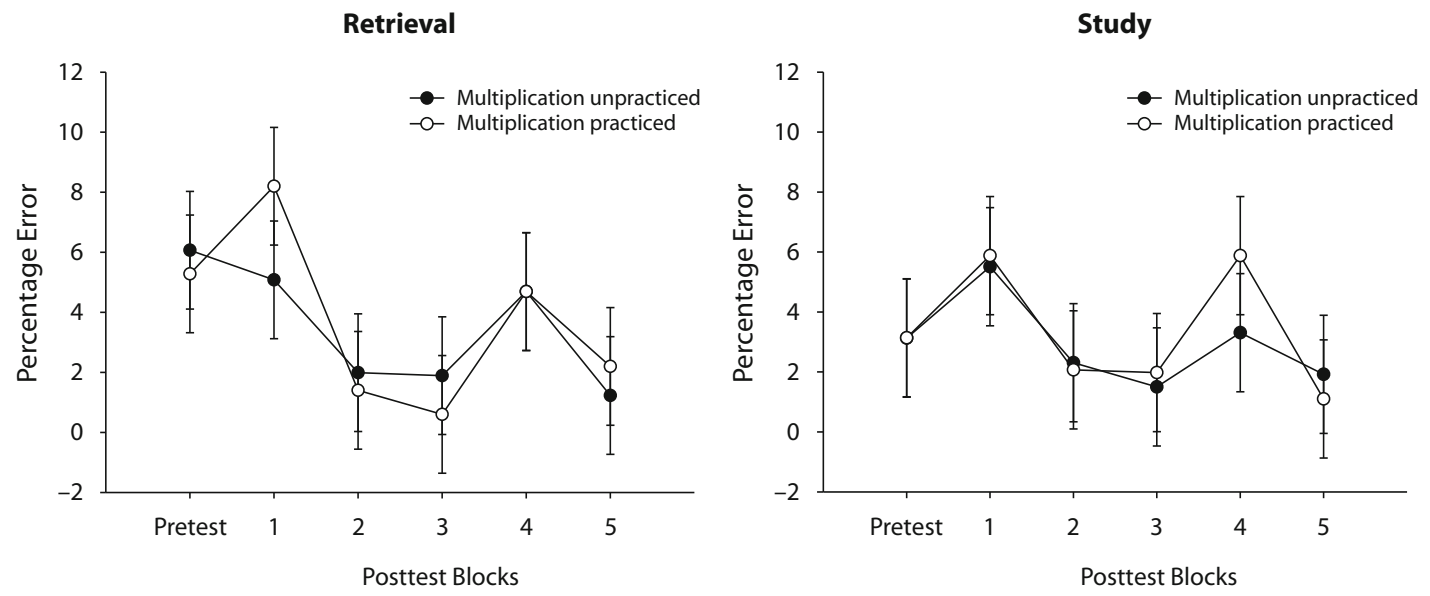

Figure 3. Mean percentages of addition errors as a function of group, set, and experimental block. Error bars are repeated measure $95 \%$ confidence intervals (Masson \& Loftus, 2003). 
tiplication retrieval equally. Multiplication intrusion errors in the first posttest block of addition (e.g., $2+5=$ 10) provided a second relevant measure. If retrieval practice created a stronger propensity to interfere with addition, we would expect more multiplication intrusions on MP addition than on MU addition problems. There were no multiplication intrusions during the pretest addition blocks, but in the first posttest block the retrieval group produced $3.5 \%$ and $0.4 \%$ multiplication intrusions for MP and MU addition problems, respectively. For the study group, intrusions occurred at a rate of $2.2 \%$ of the trials for MP and $0.4 \%$ for MU. A group $\times$ set ANOVA of the percentage of multiplication intrusions produced a main effect of set $\left[F(1,64)=8.2, M S_{\mathrm{e}}=24.7, p=\right.$ .006], reflecting more multiplication intrusions for MP addition (2.9\%) than for MU addition ( $0.4 \%)$. Most important, there was no evidence for a main effect of group $\left[F(1,64)<1, M S_{\mathrm{e}}=22.5\right]$ or for the group $\times$ set interaction $\left[F(1,64)<1, M S_{\mathrm{e}}=24.7\right]$. Thus, both retrieval and study practice promoted multiplication intrusions in the first addition block, but this effect was equivalent for the two practice conditions. This provides direct evidence that multiplication retrieval and study practice produced equal tendencies to interfere with addition. As such, interference theories of RIF would predict equivalent RIF for the retrieval and study groups. Instead, as is predicted by inhibition-based theories of RIF, only the retrieval group presented RIF in the RT analysis.

\section{DISCUSSION}

Our experiment had two main purposes. The first was to demonstrate retrieval-dependent RIF in a semantic retrieval paradigm. In the first block of the posttest, the retrieval group, but not the study group, presented RIF for MP addition problems. This demonstrates that RIF in direct semantic retrieval is retrieval dependent. This is important, because retrieval dependency is predicted by inhibition accounts of RIF, but not by an associative interference account (Anderson \& Bell, 2001; Anderson et al., 2000; Norman et al., 2007). An interference account holds that RIF arises from blocking or dilution of target activation by associative competitors and that this interference is increased when competitors are strengthened. Our analyses comparing the practiced and unpracticed multiplication target problems in the first block of the posttest demonstrated that retrieval and study practice produced equivalent benefits for the practiced problems. This is crucial because it demonstrates that retrieval and study practice did not create different retrieval propensities for multiplication. Given this, interference-based RIF should have been equivalent for the retrieval and study conditions. In contrast, the inhibition account assumes that RIF arises specifically in connection with retrieval, because only then is inhibition required to resolve associative competition. Studying a fact increases its memory strength but does not require associative discrimination and, therefore, does not engage inhibition. Consequently, as observed here, RIF occurs when a related fact is retrieved, but not when it is only studied, even though retrieval and study produced equivalent strengthening of the practiced facts.

According to Anderson (2003) and Norman et al. (2007), competitor inhibition should be relatively low when target strength is high. Consequently, a second purpose of the experiment was to compare RIF in a context of very high target strength with RIF in a context of moderate target strength. The participants in the study condition provided this comparison (right panel of Figure 2). They studied, but did not retrieve, MP multiplication counterparts for 40 blocks during the practice phase. This was expected to result in very high target strength for MP multiplication problems, whereas the unpracticed (i.e., MU) multiplication problems would have relatively low target strength. For these participants, the only retrieval practice for MP and MU multiplication problems occurred between posttest addition blocks. As was predicted, RIF in the second posttest addition block (i.e., after a single retrieval of the multiplication counterpart) was relatively small $(55 \mathrm{msec})$ when target strength was high (MP problems), as compared with the massive RIF (226 msec) when target strength was moderate. Thus, the experiment confirmed an important prediction of the Norman et al. model.

The experiment also produced an unexpected, but potentially important, result. For the retrieval group (left panel of Figure 2), the RIF effect on MU addition problems in posttest Block 2 was about twice as large as the RIF observed for MP addition problems in posttest Block 1. Thus, for the MU addition problems, one retrieval of their multiplication counterparts in the posttest produced much larger RIF than did 40 retrieval practice trials for the MP addition set. In contrast, Johnson and Anderson (2004) studied RIF in semantic retrieval and observed that cued free retrieval of semantic competitors decreased (i.e., RIF increased) with the number of related-target retrieval trials $(2,4,6$, or 8 practice trials). They proposed that semantic competitors (particularly strong competitors) are retrieved incidentally when the target is initially practiced and that this incidental retrieval strengthens the competitor and works against RIF, which emerges progressively as target strength increases with retrieval practice. Other RIF experiments have similarly found evidence that RIF increases with target retrieval practice (Levy et al., 2007; Storm, Bjork, \& Bjork, 2008; but see Macrae \& MacLeod, 1999).

How can we reconcile the evidence that RIF initially increases as the number of target retrievals increases with our finding of greater RIF after 1 target retrieval (MU addition in Block 2) than after 40 retrievals (MP addition in Block 1)? Smaller RIF effects after 40 target retrievals than after just 1 might reflect diminishing engagement of competitor inhibition, combined with priming. The principle of interference dependence (Anderson, 2003) implies that when target strength becomes sufficiently high, competitor inhibition diminishes, and this might occur relatively early on during the 40 blocks of multiplication retrieval practice. RIF of competitors built up early in practice could then decline over later practice blocks prior to the posttest. RIF has been shown to endure for up to $20 \mathrm{~min}$ (Anderson et al., 1994) but can decay substantially during 
a 24-h delay between practice and test (M. D. MacLeod \& Macrae, 2001). The durability of semantic inhibition has never been studied in the RIF literature, and it is possible that inhibition for strong semantic representations would dissipate quickly (see Anderson \& Spellman, 1995, p. 96). Furthermore, with competitor inhibition diminished, continued practice of the multiplication problems would be expected to prime, rather than suppress, their MP addition counterparts, given the similarity of the retrieval cues (e.g., $2 \times 5$ and $2+5$ ). Such priming of the MP addition facts would offset existing inhibition and would facilitate performance, relative to MU addition problems.

Beginning in Block 2 of the posttest, the pattern of mean RTs for both MP and MU addition problems was very similar for the retrieval and study groups (see Figure 2). One interpretation of this is that successful retrieval in the first addition block of the posttest released inhibition and restored MP addition and MU addition problems to similar activation levels for both groups. Differences in performance between MP addition and MU addition problems over Blocks 2-5 would then reflect differences in inhibition and RIF associated with the interpolated multiplication blocks. Inhibition would be re-created with each interpolated multiplication block and would be rereleased with each addition block, but because MP multiplication problems were extensively practiced (i.e., retrieved or studied), they initially had greater memory strength than did MU multiplication problems during the posttest. Greater strength would result in less inhibition and RIF of MP addition facts relative to MU addition facts (Anderson, 2003). This would initially produce an RT advantage for MP addition relative to MU addition, but as the retrieval strength of MU multiplication problems increased across posttest blocks, inhibition of MU addition problems would decrease and performance on MU and MP addition problems would tend to converge.

The representation and retrieval of simple addition and multiplication facts have been consistently modeled in terms of semantic memory processes (Ashcraft, 1992; Verguts \& Fias, 2005). Nonetheless, one might question whether our task provided a pure measure of semantic memory independently of episodic memory. Of course, episodic representations of addition trials would be created during the pretest, but it is unlikely that conscious recall of earlier addition trials contributed substantially to posttest addition performance. Indeed, the specific addition errors made during the posttest provide direct evidence for semantic retrieval processes. Arithmetic errors are indicative of semantic retrieval, inasmuch as they often entail semantically near or related answers (Campbell, 1994). Among the 416 addition errors recorded in the five posttest blocks, $378(91 \%)$ were semantically near ( \pm 1 or 2 from correct) or involved an operation confusion $(2+5=$ "ten"). The fact that the majority of addition errors were semantic or associative confusions provides direct evidence that semantic retrieval mediated addition performance.

Finally, could the addition RIF observed here have been caused by interference, rather than by inhibition? Several features of the data are difficult to reconcile with an inter- ference account. First, multiplication retrieval practice and multiplication study practice facilitated postpractice multiplication retrieval equally, and retrieval and study also promoted multiplication intrusions $(2+5=10)$ equally in the first posttest addition block. These results indicate that multiplication retrieval and study were equally effective at strengthening the propensity for multiplication retrieval. Given this, an interference account would predict equal RIF for the retrieval and study groups. Instead, as is predicted by the inhibition account, only the retrieval group presented RIF in the first posttest addition block. Second, RIF of addition facts was much smaller following 40 blocks of multiplication retrieval practice $(100 \mathrm{msec})$ than following a single retrieval trial $(>200 \mathrm{msec})$. This result is opposite to what an interference account would predict. Nonetheless, although there was no evidence of RIF for the study group in Block 1 of the posttest, there was evidence that multiplication study interfered with MP addition performance. The study group, like the retrieval group, presented more operation errors $(2+5=10)$ for MP addition than for MU addition in Block 1, demonstrating that multiplication study did interfere with MP performance. This interference was not expressed in RTs, but, as was discussed previously, multiplication practice without inhibition (as we assume for the study group) could prime addition facts and work against interference effects of strengthening the multiplication targets.

\section{CONCLUSIONS}

Our experiment demonstrated two important features of RIF in semantic retrieval. First, we showed that RIF in semantic retrieval is retrieval dependent, with no evidence for RIF in the study practice condition in the first posttest addition block. Furthermore, this is the only study that we know of to demonstrate retrieval-dependent RIF using an RT measure. Retrieval dependency appears to be a general feature of RIF that applies to both direct semantic retrieval and episodic recall and to both speed and probability of recall. Second, the experiment demonstrated that, with retrieval practice held constant, RIF was smaller when target strength was very high (MP problems), as compared with RIF with moderate target strength (MU problems). This supports the prediction that competitor inhibition should be low when target strength is very high, relative to when target strength is moderate (Norman et al., 2007). More generally, the present findings reinforce inhibition-based models of RIF (e.g., Anderson, 2003; Norman et al., 2007). Evidence that RIF is weaker with high target strength than when target strength is moderate cannot be easily reconciled with interference-based theories of RIF, which imply that RIF should inevitably increase with increases in target strength. In contrast, our findings follow naturally from an inhibition-based account. Competitor inhibition would have little functional value when target strength was very high (Anderson, 2003); consequently, reduced inhibition would be an adaptive response that eliminates an unnecessary expenditure of processing resources. 


\section{AUTHOR NOTE}

This research was supported by a grant from the Natural Sciences and Engineering Research Council of Canada. Address correspondence to J. I. D. Campbell, Department of Psychology, University of Saskatchewan, 9 Campus Drive, Saskatoon, SK, S7N 5A5 Canada (e-mail: jamie .campbell@usask.ca).

\section{REFERENCES}

ANDERson, M. C. (2003). Rethinking interference theory: Executive control and the mechanisms of forgetting. Journal of Memory \& Language, 49, 415-445. doi:10.1016/j.jml.2003.08.006

ANDERSON, M. C. (2005). The role of inhibitory control in forgetting unwanted memories: A consideration of three methods. In N. Ohta, C. M. MacLeod, \& B. Uttl (Eds.), Dynamic cognitive processes (pp. 159-190). New York: Springer.

ANDERson, M. C., \& BeLL, T. (2001). Forgetting our facts: The role of inhibitory processes in the loss of propositional knowledge. Journal of Experimental Psychology: General, 130, 544-570. doi:10.1037/00963445.130 .3 .544

Anderson, M. C., BJork, E. L., \& BJork, R. A. (2000). Retrievalinduced forgetting: Evidence for a recall-specific mechanism. Psychonomic Bulletin \& Review, 7, 522-530.

Anderson, M. C., BJork, R. A., \& BJork, E. L. (1994). Remembering can cause forgetting: Retrieval dynamics in long-term memory. Journal of Experimental Psychology: Learning, Memory, \& Cognition, 20, 1063-1087. doi:10.1037/0278-7393.20.5.1063

Anderson, M. C., \& Spellman, B. A. (1995). On the status of inhibitory mechanisms in cognition: Memory retrieval as a model case. Psychological Review, 102, 68-100. doi:10.1037/0033-295X.102.1.68

AshCraft, M. H. (1992). Cognitive arithmetic: A review of data and theory. Cognition, 44, 75-106. doi:10.1016/0010-0277(92)90051-I

BäUML, K.-H. (2002). Semantic generation can cause episodic forgetting. Psychological Science, 13, 356-360. doi:10.1111/j.09567976.2002.00464.x

BäUmL, K.-H., \& Aslan, A. (2004). Part-list cuing as instructed retrieval inhibition. Memory \& Cognition, 32, 610-617.

BlaXton, T. A., \& Neely, J. H. (1983). Inhibition from semantically related primes: Evidence of a category-specific inhibition. Memory \& Cognition, 11, 500-510

CAmP, G., Pecher, D., \& Schmidt, H. G. (2007). No retrieval-induced forgetting using item-specific independent cues: Evidence against a general inhibitory account. Journal of Experimental Psychology: Learning, Memory, \& Cognition, 33, 950-958. doi:10.1037/0278-7393.33.5.950

CAmpBell, J. I. D. (1994). Architectures for numerical cognition. Cognition, 53, 1-44. doi:10.1016/0010-0277(94)90075-2

Campbell, J. I. D., \& Timm, J. C. (2000). Adults' strategy choices for simple addition: Effects of retrieval interference. Psychonomic Bulletin \& Review, 7, 692-699.

CARR, T. H., \& Dagenbach, D. (1990). Semantic priming and repetition priming from masked words: Evidence for a center-surround attentional mechanism in perceptual recognition. Journal of Experimental Psychology: Learning, Memory, \& Cognition, 16, 341-350. doi:10.1037/0278-7393.16.2.341

CARR, T. H., \& Dagenbach, D. (1994). Paying attention to newly learned semantic codes. Canadian Psychology, 35, 109-110. doi:10.1037/ h0084716

Censabella, S., \& NoËL, M.-P. (2004). Interference in arithmetic facts: Are active suppression processes involved when performing simple mental arithmetic? Cahiers de Psychologie Cognitive/Current Psychology of Cognition, 22, 635-671.

Ciranni, M. A., \& Shimamura, A. P. (1999). Retrieval-induced forgetting in episodic memory. Journal of Experimental Psychology:
Learning, Memory, \& Cognition, 25, 1403-1414. doi:10.1037/02787393.25.6.1403

Johnson, S. K., \& Anderson, M. C. (2004). The role of inhibitory control in forgetting semantic knowledge. Psychological Science, 15, 448-453. doi:10.1111/j.0956-7976.2004.00700.x

Koutstaal, W., Schacter, D. L., Johnson, M. K., \& Galluccio, L. (1999). Facilitation and impairment of event memory produced by photograph review. Memory \& Cognition, 27, 478-493.

LEVY, B. J., \& ANDERSON, M. C., (2002). Inhibitory processes and the control of memory retrieval. Trends in Cognitive Sciences, 6, 299-305. doi:10.1016/S1364-6613(02)01923-X

Levy, B. J., McVeigh, N. D., MARful, A., \& Anderson, M. C. (2007). Inhibiting your native language: The role of retrieval-induced forgetting during second-language acquisition. Psychological Science, 18, 29-34. doi: $10.1111 /$ j.1467-9280.2007.01844.x

MacLeod, C. M., Dodd, M. D., Sheard, E. D., Wilson, D. E., \& BIBI, U. (2003). In opposition to inhibition. In B. H. Ross (Ed.), The psychology of learning \& motivation (Vol. 43, pp. 163-214). San Diego: Academic Press.

MacLeod, M. D., \& Macrae, C. N. (2001). Gone but not forgotten: The transient nature of retrieval-induced forgetting. Psychological Science, 12, 148-152. doi:10.1111/1467-9280.00325

Macrae, C. N., \& MacLeod, M. D. (1999). On recollections lost: When practice makes imperfect. Journal of Personality \& Social Psychology, 77, 463-473. doi:10.1037/0022-3514.77.3.463

Masson, M. E. J., \& Loftus, G. R. (2003). Using confidence intervals for graphically based data interpretation. Canadian Journal of Experimental Psychology, 57, 203-220. doi:10.1037/h0087426

Norman, K. A., Newman, E. L., \& Detre, G. (2007). A neural network model of retrieval-induced forgetting. Psychological Review, 114, 887-953. doi:10.1037/0033-295X.114.4.887

Perfect, T. J., Stark, L.-J., Tree, J. J., Moulin, C. J. A., Ahmed, L., \& Hutter, R. (2004). Transfer appropriate forgetting: The cuedependent nature of retrieval-induced forgetting. Journal of Memory \& Language, 51, 399-417. doi:10.1016/j.jml.2004.06.003

Phenix, T. L., \& Campbell, J. I. D. (2004). Effects of multiplication practice on product verification: Integrated structures model or retrieval-induced forgetting? Memory \& Cognition, 32, 324-335.

Shaw, J. S., III, BJork, R. A., \& Handal, A. (1995). Retrieval-induced forgetting in an eyewitness-memory paradigm. Psychonomic Bulletin \& Review, 2, 249-253.

Shivde, G., \& ANDERSON, M. C. (2001). The role of inhibition in meaning selection: Insights from retrieval-induced forgetting. In D. S. Gorfein (Ed.), On the consequences of meaning selection: Perspectives on resolving lexical ambiguity (pp. 175-190). Washington, DC: American Psychological Association. doi:10.1037/10459-010

SpItZer, B., \& BäUML, K.-H. (2007). Retrieval-induced forgetting in item recognition: Evidence for a reduction in general memory strength. Journal of Experimental Psychology: Learning, Memory, \& Cognition, 33, 863-875. doi:10.1037/0278-7393.33.5.863

Storm, B. C., BJork, E. L., \& BJork, R. A. (2006). When intended remembering leads to unintended forgetting. Quarterly Journal of Experimental Psychology, 60, 909-915. doi:10.1080/1747021070128 8706

Storm, B. C., BJoRk, E. L., \& BJork, R. A. (2008). Accelerated relearning after retrieval-induced forgetting: The benefit of being forgotten. Journal of Experimental Psychology: Learning, Memory, \& Cognition, 34, 230-236. doi:10.1037/0278-7393.34.1.230

VERGUTS, T., \& FIAS, W. (2005). Interacting neighbors: A connectionist model of retrieval in single-digit multiplication. Memory \& Cognition, 33, 1-16.

(Manuscript received March 31, 2008; revision accepted for publication August 27, 2008.) 